The Open Transportation Journal
CrossMark
Content list available at: www.benthamopen.com/TOTJ/
DOI: $10.2174 / 1874447801711010102$

RESEARCH ARTICLE

\title{
Assessment of the Influence of Lagos Bus Rapid Transit Scheme (BRT-Lite) on Road Traffic Crashes (RTC) on Lagos Mainland-Island Corridor
}

\author{
Adeyinka Peter Ajayi ${ }^{1,2, *}$ \\ ${ }^{I}$ Department of Transport and Tourism Studies, Redeemer University, Ede, Osun, Nigeria \\ ${ }^{2}$ Department of Geography, Fort Hare University, Alice, Republic of South Africa
}

\section{Abstract:}

\section{Background:}

This paper filled an important gap in the on-going global assessment of Bus Rapid Transit (BRT) operations on Road Traffic Crashes (RTC) safety outcomes on corridors plied.

\section{Introduction:}

The work carried out a scientific investigation of the impact of Lagos BRT-Lite(Africa's first and only BRT scheme) on the achievement of a possible reduction in the incidences of RTC on the 22-kilometer radial highway that connects Mile12 and Lagos Island the traditional central business district.

\section{Methodology:}

Secondary data on the incidences of RTC on the corridor between 2002 and 2013 were obtained from Nigeria Police. One-way Analysis of variance between subjects revealed that the advent of BRT operations on the corridor do not have any significant effect in the reported cases of the three categories of RTC examined. Minor $(p=.783)$, Serious $(p=.887)$ and Fatal $(p=.826)$.

\section{Data Analysis:}

Descriptive statistics, however, showed that there has been a general reduction in the incidences of all categories of RTC considered in the period after the commencement of BRT on the corridor.

\section{Conclusion:}

The paper concludes by positing that while it might be far-fetched to imply a direct causal relationship between the introduction of BRT and reduction in the cases of RTC on the corridor, it may not be far to suggest that it has definitely impacted safety outcomes as it relates to RTC.

Keywords: Bus Rapid Transit, Road Traffic Crashes, Lagos BRT-Lite, Assessment, One-way Analysis of variance, Public Transportation System.

\section{INTRODUCTION}

\subsection{Public Transportation System- The Pivot which Balances Livability in Contemporary Cities}

Evidences from recent transport studies in sub-Saharan Africa suggest that investments in urban road constructions

\footnotetext{
* Address correspondence to this author at the Department of Transport and Tourism Studies, Redeemer University, Ede, Osun Nigeria/ Department
} of Geography, Fort Hare University, Alice, Republic of South Africa; Tel: +2348033593676; E-mails: kunmi_ayo@yahoo.com, ajayia@run.edu.ng 
have become a major tool engaged by policy makers in ensuring the easing of congestion, saving time, reducing energy consumption, increasing safety, improving environmental outcomes and enhancement of economic development of the contemporary city [1 - 5]. It is an incontrovertible fact that urban population growth is a critical determinant in the systemic evaluation of the supply and demand dynamics of transport over time. Growth in the urban population generally equates to increment in the spatial extent of cities. This is because distances between important nodes of services, workplaces, residences and other functional units of urban life may become more dispersed. Findings from studies carried out in most sub-Saharan Africa cities suggest that recent changes in economic fortunes of city dwellers have a significant effect on the transportation systems, particularly on automobile dependency. This expulsion in the numbers of vehicles on urban routes without corresponding provision of new urban road facilities has increased rather than reduced the region's urban transport problems $[3,6,7]$.

Bearing this in mind most governments in the region made concerted efforts in recent past to increase investment in construction of new urban routes and maintenance of existing road networks [8]. For example the city of Lagos at the launch of the Lagos city Bus Rapid Transport (BRT) in 2008 projected an estimated cost of $\$ 1.7$ million for (meant for maintenance of existing routes, construction of new bus stops, procurement of vehicles etc) each kilometer of the 22 kilometers the project was to initially cover, such investment decisions on public transport system were hitherto unheard of in most cities in sub-Saharan Africa [8]. There are avalanches of literature on various dynamics and challenges of contemporary urban transportation in sub-Saharan Africa. A studied observation of most of these works showed that these challenges can be broadly grouped into two; the first are works which examined the effects that the various infrastructural deficits have on the provision of safe, effective and efficient public transport system in the region. Second, are the various researches which evaluated the fatality rates and financial burdens attributable to the ever increasing figures of reported Road Traffic Crashes (RTC). Examples of the former include researches which examined the roles that seemingly extraneous factors like crime incidences at parks along bus routes play in accessibility challenges faced by the vulnerable groups (women, young schoolchildren and the aged) in the urban space [4]. Some other works analyzed the roles played by the design and planning of the contemporary African cities in the coordination of their transportation systems [3]. While the works [9 - 11], investigated the outcomes that the provision of public transport operations has on rural/ urban transportation and its effects on health challenges generally in sub-Saharan Africa.

It is, however, discernible that the bulk of recent researches on road transport from sub-Saharan Africa are paying more attention to the causes and impacts of RTC on life expectancy, human productivity and economic development in the region, these researchers established a causal relationship between occurrences of RTC, driver's behavior, constructional defects/bad state of roads and road worthiness of both private and public vehicles [6,11-14]. It is against the backdrops of the various challenges which assailed urban transportation in sub-Saharan Africa that the present study intends to fill a noticeable gap in the literature. The study analyzed the incidences of RTC on routes that are dedicated to BRT for twelve years (2002-2013). This research undertook a comparative assessment of the incidence of RTC on the stretch of road from Ikorodu Road, through Western Avenue, and terminates at the Eko Bridge (a key 22-kilometer radial highway that connects Mile12 and Lagos Island the traditional central business district). In the build up to the launch of BRT on the said routes, systematic studies were carried out to determine the 'needs of the travelers'. The study apparently never identified RTC as one of the malaise confronting passengers on the route; rather fear of criminal attack while waiting at bus stop, fare levels, long and unreliable journey time and comfort were identified as the nagging needs.

This oversight, on its own, appears not surprising; as it looks more like the norm rather the exception in commissioned pilot studies on the viability of BRT across global cities. In Bloomberg Philanthropies (2012) sponsored studies on "Traffic safety on Bus corridor", which examined mainly traffic safety in the planning, design and operation of BRT in North America, South America, Europe, Asia and Australia, [15] observed that "Traffic safety is an aspect that has consistently been missing from publications and planning guides for Bus Rapid Transit (BRT) and Bus way corridors".

This critical gap [15], attempted to fill by carrying a study that examined the impacts of BRT on road safety in different cities on nearly a global scale. The study included Vancouver, Guadalajara, and Mexico all in North America. South American cities of Pereira, Cali, Bogota, Lima, Arequipa, Sao Paulo, Belo Horizonte, Curitiba, Rio de Janeiro and Porto Alegre. Izmit(Turkey) in Europe. Delhi, Ahmadabad, Indore in Asia and Australian city of Brisbane. The research, however, omitted the city of Lagos, which is operating the first BRT among African cities. This study, therefore among other factors is an attempt to fill this important gap. Statistical figures obtained from Nigeria Police 
records (Table 1) implied that RTC incidences on the route before and after the launching of BRT painted a worrisome picture. Such important variable should have been incorporated into the Lagos BRT pilot study from the very onset and contingency plans on how best to sustainably tackled it spelled out. This oversight becomes more perturbing when it is realized that one of the preparatory steps undertaken before the launch of BRT was minor redesigning and reconstruction of the $22 \mathrm{~km}$ routes stretch dedicated to the BRT operation. The remaining parts of this work are arranged thus, after this section, comes, the next dedicated to literature review which is closely followed by the section on theoretical/modeling underpinning for the discourse. The section on analysis and discussion of the findings are next, the concluding section fittingly ends the discourse.

Table 1. Reported cases of Road Traffic Crashes (RTC) on Lagos BRT Route 2002-2013.

\begin{tabular}{|c|c|c|c|}
\hline Years & Serious Cases & Fatal Cases & Minor Cases \\
\hline 2002 & 296 & 235 & 364 \\
\hline 2003 & 444 & 276 & 477 \\
\hline 2004 & 306 & 187 & 377 \\
\hline 2005 & 347 & 244 & 267 \\
\hline 2006 & 324 & 236 & 396 \\
\hline 2007 & 295 & 214 & 582 \\
\hline 2008 & 533 & 275 & 257 \\
\hline 2009 & 280 & 182 & 327 \\
\hline 2010 & 222 & 223 & 410 \\
\hline 2011 & 318 & 222 & 406 \\
\hline 2012 & 312 & 256 & 399 \\
\hline
\end{tabular}

Source: The Nigeria Police, Lagos State Command 2015.

\section{MATERIALS}

\subsection{Review of BRT Operations and their Influence on Safety Outcomes}

Findings from the study conducted revealed that BRT implementation in Guadalajara (in Mexico) and in Bogota (Columbia) contributed in significant proportions to reductions in crashes and fatalities on their respective corridors (46\% reduction in RTC in Guadalajara and staggering 60\% reduction in Bogota) [15]. Statistical figures supplied [16]. complimented the results available from the findings [15]. The result showed that there is consistent improvement in safety reportage on Bogota BRT routes, accidents were found to have decreased by $79 \%$, fatalities along trunk lines also fell by $92 \%$, while report of Road Traffic Injuries (RTI) decreased by $75 \%$.Results such as this, however, can be misleading, if one is to conclude that BRT has a definite positive impact on accident reduction on route plied. Statistical analysis obtained from the study carried out in Belo Horizonte (Brazil) revealed that the street/route which the BRT runs on has the highest crash frequencies citywide. In the case of Delhi city BRT, crashes and fatalities were, shockingly, found to increase after the implementation of BRT system [15, 17].

\subsection{Review of Lagos BRT Operation}

There has been a series of studies which undertook different form of assessment of the BRT on Lagos route since it was launched [18 - 20]. In empirical researches it has been concluded that the advent of BRT has significant impact on ensuring passengers' movement and comfort in Lagos metropolis [8]. In a study holistically examined the definition, process, and performance of the Lagos metropolis BRT-Lite system. The study attributed the obvious success of the scheme to the following; first, the ability of Lagos Metropolitan Transport Authority (LAMATA) as a public transport authority to critically articulated perceived success factors and thereafter planned, regulated, and formed relationships with concerned investors to ensure the delivery of public transport services based on the articulated factors. Second, the pivotal roles played by political commitment given by leaders in government helped in achievements of set targets of the scheme. Lastly the ability to deliver a public transport system which is affordable and which operational standard conforms to international best practices made the sustainability of the scheme realizable [21]. The impact of series of technical innovations surrounding the operations of the BRT system in Lagos metropolis has been reviewed .The study, in particular, evaluated how the introduction of innovative concepts and structures like BRT terminals and stations, dedicated lanes and bilateral stations, median stations, provision of colored delineators and colorized pavement on intersections has helped in the achievement of sustainable service delivery of the system. It is, however, discernible that 
most of these works paid scant attention to the evaluation of how impactful the advent of BRT has been on RTC on the corridor it transverses on. It may be assumed that this oversight may be connected to the fact that the reported RTC cases are not only on the dedicated BRT lanes but also on the adjoining lanes as well. Nevertheless there is a need to evaluate the impact that BRT operations has on reported RTC rates on the road corridor it transverses, this is germane because one of the key guiding principles behind the introduction of the scheme is to reduce numbers of both private and public vehicular traffic, an established catalyst to RTC reduction on road corridors [8].

\section{THEORETICAL FRAMEWORKS}

Shreds of evidence from literature revealed that there has been concerted overtime to provide models/theories that explained the process involved with the occurrences of road crashes [22]. Attempted a holistic review of different theories or models used in the analysis of accidents in the last 100 years. The three earliest sets of models are:
i. Accidents as random events
ii. Accident proneness theory
iii. The causal model.

All followed a simple rule or modeling assumption: an accident is a random event which is largely caused by some drivers with specific characteristics. While some can argue that these earlier models and theories appeared simplistic in their explanation of a rather complex phenomenon- (RTC), wholesome condemnation of these models can be a grievous error. They provide a practical guidance to the understanding of RTC. The accident as a complex system theory offered a paradigm shift from this body of earlier theories/models in the analysis of RTC [22, 23]. The theory opined that a complete scientific explanation for accidents is not possible [22]. It is, therefore, necessary to create accident causation models which guide the researcher in finding solutions to avoid accidents. The systemic approach characterizes the occurrence of the accident on the basis of the system as a whole, rather than on the level of specific cause-effect [24]. A more recent theoretical underpinning with an attempt at synthesizing all these previous theories/models is the DriverVehicle-Environment (DVE) system [22]. Herein it is broadly believed that "behavior in road accidents is complex, within a complex system that consists of the triptych Driver-Vehicle-Environment" [22]. The proponents of this school of thought [23 - 25] further argued that accidents are not complex because of, first, the number of components involved in the accident occurrence, second, a number of variables interacting during its occurrence, and third, the number of their interactions. Rather, it is often the impossibility to predict the DVE system behavior that defines this complexity. This unpredictability is mainly attributable to the fact that human actions are strongly involved in accident causation, and that human behavior is unpredictable. The DVE appeared to be most appropriate in the analysis of RTC for the purpose of this research; it offers a theoretical lens for a concise view to analyze the rate of RTC on this BRT route according to the three sub-components - the driver, the vehicle and the environment. The carving out of a separate BRT route from the existing highway corridor as undertaken by the LAMATA is definitely a re-invention of the "driving environment". Similarly, the advent of BRT vehicles (mostly brand new buses) being driven by specially trained drivers is a novel which should ordinarily have telling impact on RTC in the Nigerian milieu where this study is performed.

\section{METHODOLOGY}

\subsection{Data Procedure and Ethical Consideration}

The study utilized secondary data. Records of Road Traffic Crashes (RTC) on the studied BRT corridor for twelve years (six years before the commencement of BRT on the corridor and six years after it began operation) were obtained from the Police Record Unit of The Nigeria Police, Lagos State Command. The Lagos State Police Command released the record being fully aware that the data would only be used for research purposes.

\subsection{Data Processing}

First, descriptive statistics (table and graph) showed the trend of the incidences of the reported cases of RTC on the corridor for the period reviewed. A one-way Analysis of Variance (ANOVA) was conducted in order to compare the effects of BRT operations on the incidences of Serious, Fatal and Minor cases of RTC. The one-way between subjects ANOVA was conducted to compare the effect of BRT operations on the corridor studied by comparing the incidences of Serious, Fatal and Minor incidences of RTC before the commencement of BRT and after its commencement. All statistical analyses were performed using IBM SPSS (Statistical Package for Social Sciences), version 23. 


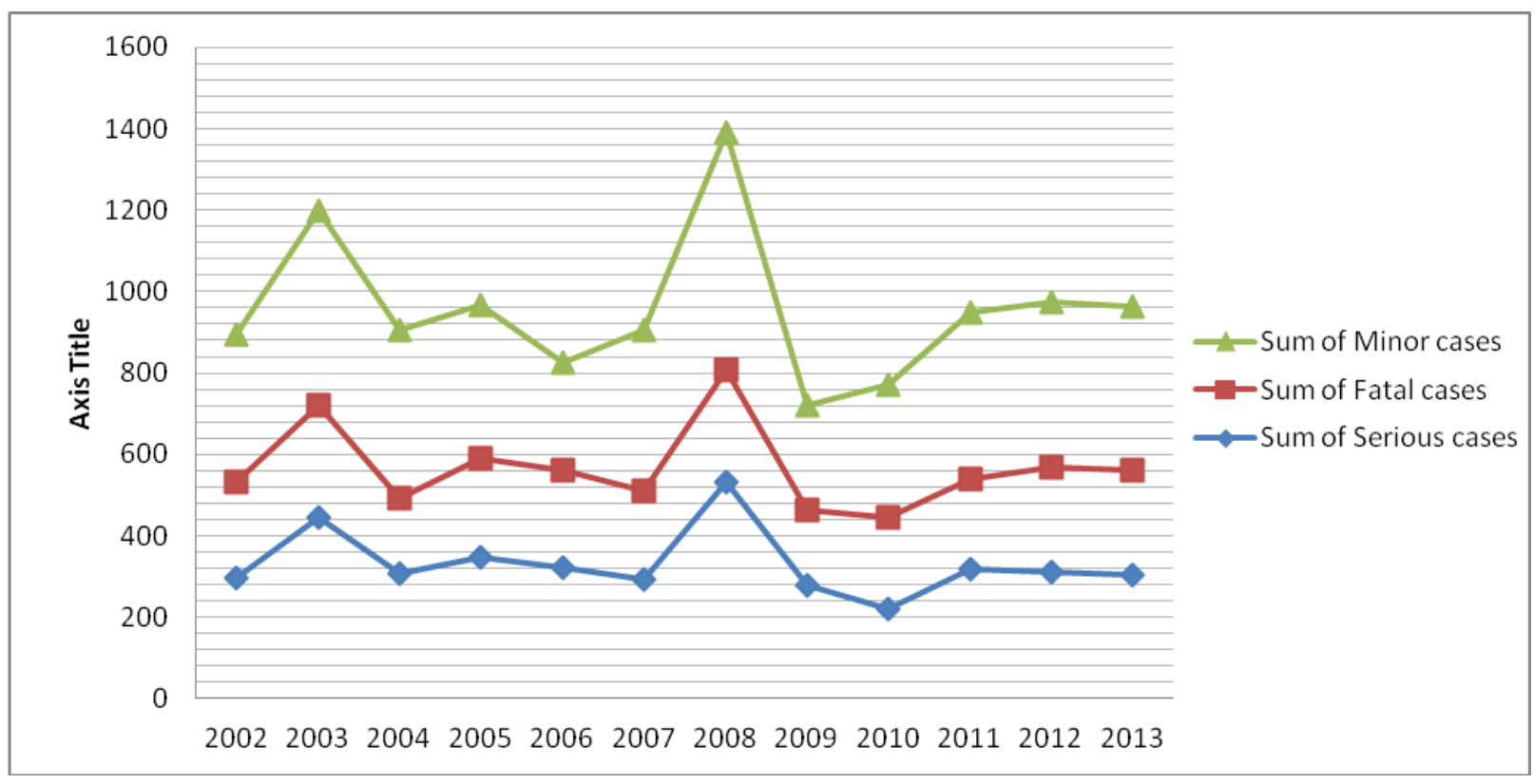

Fig. (1). Graphical representation of minor, serious and fatal RTC on the main Lagos BRT route 2002 and 2013.

The main hypothesis derived is;

Ho; there are no significant differences in the reported fatal, serious and minor RTC before and after the introduction of BRT on the road corridor.

\subsection{Result and Discussion}

The data from the Nigeria Police used in this analysis were categorized by the Police Authority into minor, serious and fatal cases of RTC. The premise for the categorization is based on the fact that the impact resulting from each accident case differs. Minor cases of RTC are those with no resultant bodily injuries, the damages done to the vehicles are also not extensive and can be fixed at a relatively cheaper cost. Serious cases of RTC are the accidents in which they are more severe impacts.

There must be severe or grievous bodily injuries of victims involved, the vehicles involved must also have some serious damages which can be fixed at a high cost or are "total write-off" (irreparable). Fatal cases of RTC are so categorized to represent a situation when there is an immediate death of at least one of the victims of the accident. It should be noted that some cases of RTC which can be initially designated as "Serious" could end up been finally categorized as "Fatal", this will happen if the injured victims passed on from the injuries sustained during the accident afterward.

The information gleaned from both the descriptive and inferential statistical analyses done on the record of the RTC for the period under consideration painted a gory and worrisome one. The Lagos BRT project was launched in 2008 , surprisingly the year had the highest incidences of all categories of RTC (minor, serious and fatal) considered in this study (Table 1 and Fig. (1)), while the factors responsible for this might be a subject for further study, it is, however, apparent that there has been uneven decrease in the reported cases of RTC under the 3 designated categories in the years after.

Inferential statistical analysis showed that none of the three categories of reported RTC on the studied Lagos BRT route (Serious, Fatal and Minor) differed significantly for the period considered. The result from the one-way between subjects ANOVA (Tables 2, 3 and 4) that was conducted to compare the effect of BRT operations on the incidences of the three cases (serious, fatal and minor) of RTC for the period considered showed that there was no significant effect of the operations of BRT on incidences of all three cases of RTC on the corridor studied for the years considered (between 2002-2013). ANOVA result of the impact of BRT operation on serious incidences of RTC (Table 2) at $p<.05$ level is $[\mathrm{F}=(1,11)=.021, p=.887]$. While ANOVA test of significance for fatal (Table 3) and minor (Table 4) cases showed the same trend $\{$ fatal- $p<.05$ is $[\mathrm{F}=(1,11)=.051 . p=.826$ and minor- $p<.05$ is $[\mathrm{F}=(1,11)=.080, p=.783\}$. These results suggest that the commencement of the operation of BRT on the corridor studied do not have significant effects 
on the reduction in the incidences of serious, fatal and minor RTC. However, it should be noted that there was a noticeable decline in the incidences of the three categories of RTC in the year after the BRT began operations on the road corridor (Table 1).

Table 2. One-way analysis of variance of serious cases of RTC by the introduction of BRT on the road corridor.

\begin{tabular}{|c|c|c|c|c|c|}
\hline Source & SS & DF & MS & F & P \\
\hline Between Groups & 154.083 & 1 & 154.083 & .021 & .887 \\
\hline Within Groups & 72604.167 & 10 & 7260.417 & & \\
\hline Total & 72758.250 & 11 & & & \\
\hline
\end{tabular}

Source: Author's Analysis

Table 3. One way analysis of variance of fatal cases of RTC by the introduction of BRT on the road corridor.

\begin{tabular}{|c|c|c|c|c|c|}
\hline Source & SS & DF & MS & F & P \\
\hline Between Groups & 52.083 & 1 & 52.083 & .051 & .826 \\
\hline Within Groups & 10184.833 & 10 & 1018.483 & & \\
\hline Total & 10236.917 & 11 & & & \\
\hline
\end{tabular}

Source; Author's Analysis

Table 4. One way analysis of variance of minor cases of RTC by the introduction of BRT on the road corridor.

\begin{tabular}{|c|c|c|c|c|}
\hline Source & SS & DF & MS & F \\
\hline Between Groups & 660.083 & 1 & 660.083 \\
\hline Within Groups & 82614.833 & 10 & .080 & .783 \\
\hline Total & 83274.917 & 11 & & \\
\hline
\end{tabular}

Source: Author's Analysis

There was a 52. 53\% decline in the incidences of serious RTC between 2008 (the year BRT was launched) and 2009 (the year after the commencement of BRT operation on the corridor). There was also a sharp decline of $66.18 \%$ in the incidences of fatal RTC on the road corridor between 2008 and 2009. For minor cases of RTC there was a $44.15 \%$ reduction in the occurrences between 2008 and 2009. There is no doubt that the introduction of BRT on the route must have positively affected the operational "environment" as conceptualized under the DVE model [22] as there has been continuous effort to improve the entire structural components of the highway under consideration. Efforts should however be made to avoid the simplistic belief that the "reconstruction" of the existing highway on its own is a panacea to the problem of RTC reduction on the corridor [26 - 28]. It has been observed that reconstruction works on existing road corridor such as carving out a narrow lane dedicated to the operation of BRT may have negative impact on the workload experienced by drivers. Results from these studies [26 - 28] confirmed that one of the side effects of lanewidth reduction is that drivers tend to move closer towards the edge line in the absence of oncoming traffic. This on its own could increase the risk of single vehicle accident because of the danger of run-off-road collisions.

It is therefore suggested that the triptych components of the DVE model-the driver, vehicle and environment, must be subjects of intense studies and major policy changes if there is any sincere desire to reduce the reported cases of RTC on the road corridor. In a similar vein, [29] in a recent study which focused on comparative analyses of the occupational challenges experienced among BRT drivers and other urban public transit drivers, established a strong nexus between high level of stress and urban public bus driving. It is the opinion of the researchers [29, 30] that prevention of occupational traffic crashes among different categories of urban bus drivers could be achieved through different intervention strategies which effectively manage work stress and burnout. In line with this advise, it is been advocated that the Lagos BRT system is fully automated. For example, the ticketing system needs to be digitally operated. This will reduce the waiting time at each bus stop where manual ticket verification causes unnecessary delay and increase the numbers of hours spend by the drivers behind the wheels.

\section{CONCLUSION}

This research, intends to fill an important gap in an on-going global discourse on the influence that BRT scheme has on safety outcomes on routes transverse in different cities where it is operational [15]. In 2013 injuries sustained from RTC are the eighth leading cause of mortality and the tenth cause of disability in the world. The debilitating effect of 
this type of burden is most disturbing in sub-Saharan Africa which is the region with world poorest countries [25]. Using secondary data of reported cases of RTC provided by Nigeria Police, the study employed both descriptive and inferential statistical techniques to examine if there have been differences in the reported cases of minor, serious and fatal RTC between 2002-2013 a period which covered 6 years before, and 6 years after the introduction of BRT on the route. The DVE model provided theoretical guidance to analyze the influence that the triptych of driver, vehicles and environment on the route which the BRT operated upon has on RTC for the period under review [22]. One-way analysis of variance showed that the introduction of BRT operations on the road corridor studied has not significantly affected the incidences of the three categories of RTC examined. This is because there were no significant differences in the reported cases of the three categories of RTC before and after the introduction of BRT on the road corridor. Findings from this pilot study showed that, while, it might be farfetched to conclude that there are no definite casual relationship between the introduction of BRT on the studied route and a definite changes in the safety outcomes as it relates to incidences of RTC, it might be safe to posit that the introduction of BRT on the 22 kilometer highway radial between the mainland and island sections of Lagos metropolis has some effect on the safety outcomes on the route. This finding is not in any way different from similar studies of 18 cities considered in a global research carried out by [15, 17], results from their researches seem to imply that there is a significant reduction in the incidences of RTC after the introduction of BRT on some routes considered in some cities, while, strangely BRT seems to has deepened the problem in some cities!

Due to its many benefits, BRT is one of the most environmentally sustainable options when exploring options for public transit system in densely populated cities both now and the future, it is therefore necessary that the impact of BRT on RTC safety outcomes on corridors plied is the subject of further intense investigations by planners and designers of the scheme.

\section{CONSENT FOR PUBLICATION}

Not applicable.

\section{CONFLICT OF INTEREST}

The authors declare no conflict of interest, financial or otherwise.

\section{ACKNOWLEDGEMENTS}

Declared none.

\section{REFERENCES}

[1] World Bank, Cities on the move; a World Bank urban transport strategic review, 2002.

[2] World Health Organization, Supporting a decade of action, vol. 1, no. 318, 2013.

[3] R.E Msigwa, "Challenges Facing Urban Transportation in Tanzania", Mathemat. Theor. Modeling., vol. 3, no. 5, pp. 18-25, 2013.

[4] A.P. Ajayi, and D.D. Ajayi, "Areal differentiation in crime in public transit terminals in Ibadan metropolis", J. Transp. Secur., vol. 6, no. 1, pp. 1-12, 2013.

[http://dx.doi.org/10.1007/s12198-012-0099-2]

[5] D. Ajayi, and A. Ajayi, "Trend Analysis of Crime Incidences and Crime Vulnerability Differentials on Urban Transport Facilities in Ibadan", J. Intell. Transport. Urban Plann, vol. 2, no. 2, pp. 45-57, 2014.

[6] M. Simoonga, Road safety in Lusaka city and community approaches to road safety. Lusaka City Council, 2009 Accessed on: www.gtkp.com/userfiles/LCC\%20road\%20safety\%20in\%20Lusaka\%20city.pdf

[7] A.P. Ajayi, "Analytical study of supply chain collaboration guiding forestry products supply in a developing economy", Int. J. Bus. Perform. Supply Chain Modell., vol. 8, no. 4, 2016.

[8] D. Mobereola, "Africa first Bus Rapid Transit scheme. The Lagos BRT-Lite system. Sub-Saharan Africa Transport Policy Program (SSATP)", Discussion Paper No 9. Urban Transport Series, 2009.

[9] M.A. Adetunji, and O. Aloba, "The level of compliance of commercial motorcyclists to traffic rules on urban roads in south western nigeria", J. Edu. Soci. Res. MCER, vol. 4, no. 3, pp. 345-352, 2014.

[10] D.M. Matheka, F.O. Alkizim, C. Kipsania, and J. Wike, "Road traffic injuries in Kenya; A survey of commercial motorcycles drivers", Pan Afr. med. J., vol. 21, no. 1, 2015.

[11] S. Jones, "M., Tefe, S., Zephaniah, E.,Telda and S., Appiah-Opoku “ Public transpiration and health outcomes in rural sub-Sahara Africa-A synthesis of professional opinion"", J. Transp. Health, vol. 3, no. 2, pp. 211-219, 2016.

[http://dx.doi.org/10.1016/j.jth.2015.12.005] 
[12] O. A. Atubi, "Determinants of Road Traffic Accident Occurrences in Lagos state: Some Lessons for Nigeria", Int. J. Humanities. Social Sci., vol. 2, no. 6, pp. 252-259, 2012.

[13] A.J. Aderamo, "Road Traffic Accident Injuries and Productivity in Nigeria", J. Asian Scientific Res., vol. 2, no. 7, pp. 334-344, 2012.

[14] Y. Dabebe, Road traffic accident and human security in Addis-Ababa. . Amazon.com, 2014. [E book].

[15] N. Duduta, C. Adriazola, C. Wass, D. Hidalgo, and L. Lindau, Traffic safety on Bus corridor; Guidelines for integrating pedestrians and traffic safety into the planning, design and operation of BRT, Bus way and bus lanes., EMBARQ Bloomberg Philanthropies Sponsored studies, 2015.

[16] M. Turner, C. Kooshian, and S. Winkelman, "Colombia's Bus Rapid Transit (BRT) Development and Expansion." An Analysis of barriers and critical enablers of Colombia's BRT systems. Centre for Clean Air Policy (CCAP), World Transmit. Res. 2012

[17] N Duduta, C Adriazola, D Hidalgo, LA Lindau, and R Jaffe, "Understanding road safety impact of high-performance Bus Rapid Transit and busway design features", J. Transp. Res. Board., vol. 2317, no. -1, pp. 8-14, 2012. [http://dx.doi.org/10.3141/2317-02]

[18] A.O. Ogunkoya, "Public transportation innovation; The impact of BRT on passenger movement in Lagos metropolitan area", Medwell. J., vol. 5, no. 8, pp. 845-852, 2008.

[19] A Somuyiwa, "Impact of Bus Rapid Transit on passenger satisfaction in Lagos metropolis", Int. J. Creativity. Tech. Develop., vol. 1, no. 3, 2009.

[20] K.T. Gbadamosi, "An evaluation of the impact of bus rapid transit in urban intracity passenger movement in Lagos State", In: Being the Full length of a paper, WCTR, Lisbon, 2010.

[21] D. E. Amiegbebhor, J. B. Akarakiri, and O. F. Dickson, "Evaluation of Technical Innovations in Bus Rapid Transit System in Lagos State", Adv. Research., vol. 6, no. 2, pp. 1-12, 2015.

[22] T. Hermitte, Review of accident causation models used in road accident. Research of EC FP7 project, DaCoTa, 2012.

[23] W. Ben Ahmed, M. Mekhilef, M. Bigand, and Y. Page, "Knowledge sharing between designer and accidentologists for the development of road safety system", DETC 2005-85181, ASME 2005 Design Engineering Technical Conference, Long Beach Calif., SEPTEMBER 24-28. 2005 [http://dx.doi.org/10.1115/DETC2005-85181]

[24] E. Hollnagel, Barrier and accident prevention., Ashgate: Aldershot, U.K., 2004.

[25] World Health Organization, Global status report on road safety, 2013.

[26] S. Mecheri, F Rosey, and R Lobjois, "The effects of lane width, shoulder width, and road cross-sectional reallocation on drivers' behavioral adaptations", Accid Anal. Prev., no. 104, pp. 65-73, 2017.

[27] ERSO (European Road Safety Observatory). Traffic Safety Basic Facts on Single Vehicle Accidents. European Commission, Directorate General for Transport June, 2015.

[28] C. Dijksterhuis, K.A. Brookhuis, and D. De Waard, "Effects of steering demand on lane keeping behaviour, self-reports, and physiology. A simulator study", Accid. Anal. Prev., vol. 43, no. 3, pp. 1074-1081, 2011.

[http://dx.doi.org/10.1016/j.aap.2010.12.014] [PMID: 21376904]

[29] S. Useche, B. Cendales, F. Alonso, and A. Serge, "Comparing Job Stress, Burnout, Health and Traffic Crashes of Urban Bus and BRT Drivers", Am. J. Appl. Psychol., vol. 5, no. 1, pp. 25-32, 2017.

[30] B. Cendales-Ayala, S.A. Useche, V. Gómez-Ortiz, and J.P. Bocarejo, "Bus Operators' Responses to Job Strain: An Experimental Test of the Job Demand-Control Model", J. Occup. Health Psychol., 2016. [Epub ahead of print]

(C) 2017 Adeyinka Peter Ajayi.

This is an open access article distributed under the terms of the Creative Commons Attribution 4.0 International Public License (CC-BY 4.0), a copy of which is available at: (https://creativecommons.org/licenses/by/4.0/legalcode). This license permits unrestricted use, distribution, and reproduction in any medium, provided the original author and source are credited. 